\title{
Paraneoplastic retinopathy associated with retroperitoneal liposarcoma
}

This article was published in the following Dove Press journal:

Clinical Ophthalmology

27 March 2010

Number of times this article has been viewed

\author{
Mineo Kondo' \\ Kumiko Mokuno² \\ Ai Uemura' \\ Shu Kachi' \\ Makoto Nakamura' \\ Atsuya Kondo 3 \\ Hiroko Terasaki' \\ 'Department of Ophthalmology, \\ Nagoya University Graduate School \\ of Medicine, Nagoya, Japan; \\ ${ }^{2}$ Department of Ophthalmology, \\ ${ }^{3}$ Department of Urology, Kariya \\ Toyota General Hospital Kariya, Japan
}

Correspondence: Mineo Kondo

Department of Ophthalmology, Nagoya

University Graduate School of Medicine,

65 Tsuruma-cho, Showa-ku, Nagoya

466-8550, Japan

Tel +8I 527442277

Fax +8I 527442278

Email kondomi@med.nagoya-u.ac.jp

\begin{abstract}
We report a case of paraneoplastic retinopathy associated with a retroperitoneal liposarcoma. A 42-year-old man was referred to our hospital with complaints of night blindness and blurred vision in the peripheral field. Electroretinograms showed a progressive amplitude reduction in his both eyes. Abdominal magnetic resonance imaging showed a large retroperitoneal mass, and pathologic examination revealed a dedifferentiated liposarcoma. Western blot analysis showed an antiretinal antibody in the serum of our patient, and his serum reacted with the photoreceptors of a bovine retina. To the best of our knowledge, this is the first case of paraneoplastic retinopathy associated with a liposarcoma.
\end{abstract}

Keywords: paraneoplastic retinopathy, retroperitneal liposarcoma, electroretinogram, cancerassociated retinopathy

\section{Introduction}

Paraneoplastic retinopathy $(\mathrm{PR})$ is a progressive retinal disease caused by antibodies generated from neoplasms distant from the eye..$^{1-3}$ The retinopathy can develop either before or after the diagnosis of the neoplasm. Patients with PR usually have night blindness, photopsia, ring scotoma, attenuated retinal arteriole, and abnomal electroretinograms (ERGs). PR is thought to be mediated by an autoimmune mechanism, and is associated with the presence of antiretinal autoantibodies in the serum.

Various types of neoplasms are known to cause PR, including malignancies of the lung, breast, cervix, colon, prostate/bladder, uterus/endometrium, and blood cells. Only two cases of PR associated with a sarcoma, a malignant tumor arising from mesenchymal cells, have been reported. ${ }^{4,5}$ We report a case of PR associated with a retroperitoneal liposarcoma. The patient's visual symptoms preceded the discovery of the tumor by six months.

\section{Case report}

A 42-year-old man was referred to our hospital with complaints of night blindness and blurred vision in the peripheral field. He did not have any systemic or eye diseases including a malignant tumor, and the family history revealed no other members to have any eye diseases.

At the initial examination, his best-corrected visual acuity was 1.0 in both eyes, but Goldmann perimetry showed defects in the mid-peripheral visual fields in both eyes (Figure 1A). Ophthalmoscopy showed that the fundus was nearly normal, but fluorescein angiography demonstrated mottled hyperfluorescence along the vascular 
arcades (Figure 1B and 1C). The ERG amplitudes of both the rod and cone components were reduced (Figure 1D, middle column). Based on these findings, we diagnosed him as having a rod-cone dystrophy.

However, his symptoms progressively worsened, and the amplitudes of the ERGs were further reduced six months after the initial examination (Figure 1D, right column). We then suspected PR, and performed systematic magnetic resonance imaging (MRI). The abdominal MRI showed a large retroperitoneal mass (Figure 2A, arrow) which compressed the left kidney.

We also performed Western blot analysis using bovine retinal proteins to determine whether there were any antiretinal antibodies in the serum of our patient. A retinal protein of approximately $83 \mathrm{kD}$ (Figure $2 \mathrm{~B}$, arrow) was detected in the serum of this patient. We also confirmed that the serum reacted with the photoreceptors of a bovine retina (Figure 2C).

A
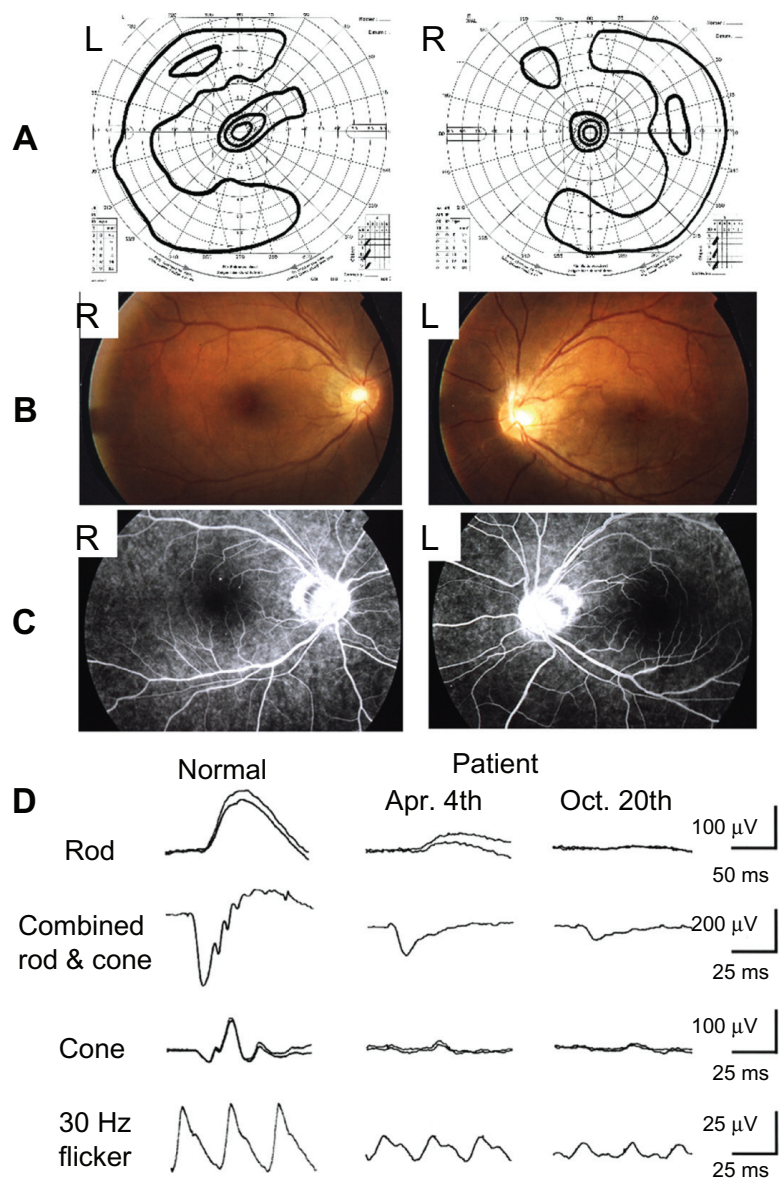

Patient

Figure I Ophthalmologic findings in a case of paraneoplastic retinopathy. A) Visual field obtained by Goldmann perimetry showing ring scotomas in both eyes. B) Fundus photographs of our patient. C) Fluorescein angiograms of our patient. D) Results of full-field ERGs.The ERG amplitudes of both the rod and cone components are reduced and were smaller at the six-month followup examination.

Abbreviation: ERG, electroretinogram.
We then diagnosed our patient as having PR associated with retroperitoneal tumor, and the tumor as well as the left kidney was removed (Figure 2D). Pathologic examination revealed a dedifferentiated liposarcoma that contained the characteristic two patterns of a well differentiated liposarcoma (Figure 2E, asterisk) and dedifferentiated fibrotic sarcomatoid tissue (Figure 2E, arrow). After the tumor was resected, he received chemotherapy but he had a recurrence with metastasis. His status became unknown after he moved to his hometown for terminal care.

\section{Comments}

A PubMed search for cases of PR associated with a sarcoma yielded two cases. ${ }^{4,5}$ One case involved a uterine sarcoma, and the other a rhabdomyosarcoma of the thorax. To the best of our knowledge, this is the first case of PR associated with a liposarcoma. A liposarcoma is
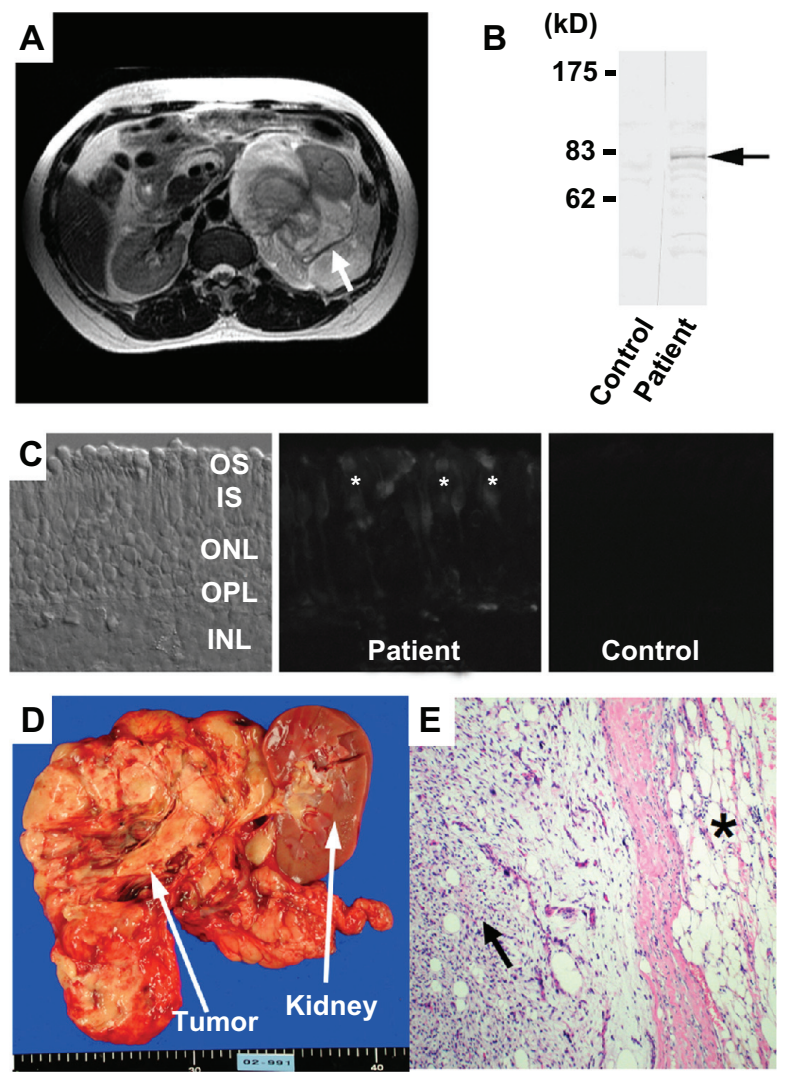

Figure 2 Systemic and histologic findings in a case of paraneoplastic retinopathy. A) Abdominal MRI showing a large retroperitoneal mass (arrow), which compressed the left kidney. B)Western blot analysis of patient's serum using bovine retinal protein. The serum reacted to an $83 \mathrm{kD}$ antigen (arrow). C) Immunohistochemical analysis using patient's serum demonstrates autoreactivity against the photoreceptors of bovine retina. D) Gross appearance of tumor. E) Microscopic appearance of retroperitoneal tumor $(\times 20)$. Two characteristic patterns of well differentiated liposarcoma (asterisk) and dedifferentiated fibrotic sarcomatoid tissue (arrow) can be seen.

Abbreviations: OS, outer segment; IS, inner segment; ONL, outer nuclear layer; OPL, outer plexiform layer; INL, inner nuclear layer; MRI, magnetic resonance imaging. 
a malignancy of fat cells that occurs in deep soft tissue and is mostly seen in the limbs and retroperitoneum. ${ }^{6}$ It is the most common soft tissue sarcoma and accounts for approximately $20 \%$ of all mesenchymal tumors. Most of the patients with liposarcoma have no symptoms until the tumor becomes large and causes pain or functional disturbances in neighboring organs.

We detected an antiretinal antibody in the serum of our patient, and found that the serum reacted with the photoreceptors of a bovine retina, suggesting that this antibody caused the retinopathy of our patient. However, we did not confirm that this antibody actually reacted to the tumor proteins of our patient. Thus, additional experiments are needed because it is known that the antiretinal antibody can be produced not only in PR, but also in other retinal degenerative diseases as a secondary complication of retinal cell death. ${ }^{7}$

Our experience with this case demonstrated that it is important for ophthalmologists to be aware that liposarcoma can be the cause of PR. In these cases, the visual symptoms may precede the discovery of this tumor, because liposarcoma usually grows silently in deep soft tissues without any local symptoms.

\section{Acknowledgments}

Grant support for this research was received from Health Sciences Research Grants (H16-sensory-001) from the Ministry of Health, Labor and Welfare, Japan, and Ministry of Education, Culture, Science and Technology (Numbers 18591913 and 18390466), Japan.

\section{Disclosures}

The authors report no conflicts of interest in this work.

\section{References}

1. Thirkill CE, FitzGerald P, Sergott RC, et al. Cancer-associated retinopathy (CAR syndrome) with antibodies reacting with retinal, optic-nerve, and cancer cells. N Engl J Med. 1989;321:1589-1594.

2. Adamus G. Autoantibody targets and their cancer relationship in the pathogenicity of paraneoplastic retinopathy. Autoimmun Rev. 2009;8:410-414.

3. Chan JW. Paraneoplastic retinopathies and optic neuropathies. Surv Ophthalmol. 2003;48:12-38.

4. Eltabbakh GH, Hoogerland DL, Kay MC. Paraneoplastic retinopathy associated with uterine sarcoma. Gynecol Oncol. 1995;58:120-123.

5. Hammerstein W, Jürgens H, Göbel U. Retinal degeneration and embryonal rhabdomyosarcoma of the thorax. Fortschr Ophthalmol. 1991;88:463-465.

6. Ferrario T, Karakousis CP. Retroperitoneal sarcomas: Grade and survival. Arch Surg. 2003;138:248-251.

7. Heckenlively JR, Ferreyra HA. Autoimmune retinopathy: A review and summary. Semin Immunopathol. 2008;30:127-134.
Clinical Ophthalmology

\section{Publish your work in this journal}

Clinical Ophthalmology is an international, peer-reviewed journal covering all subspecialties within ophthalmology. Key topics include: Optometry; Visual science; Pharmacology and drug therapy in eye diseases; Basic Sciences; Primary and Secondary eye care; Patient Safety and Quality of Care Improvements. This journal is indexed on

Submit your manuscript here: http://www.dovepress.com/clinical-ophthalmology-journal

\section{Dovepress}

PubMed Central and CAS, and is the official journal of The Society of Clinical Ophthalmology (SCO). The manuscript management system is completely online and includes a very quick and fair peer-review system, which is all easy to use. Visit http://www.dovepress.com/ testimonials.php to read real quotes from published authors. 